\title{
Relationships between fetal body weight of Wistar rats at term and the extent of skeletal ossification
}

I. Chahoud and F.J.R. Paumgartten
Institute of Clinical Pharmacology and Toxicology, Department of Toxicology, Charité University Medical School, Campus Benjamin Franklin, Berlin, Germany

\section{Correspondence \\ I. Chahoud \\ Garystraße, 5 \\ 14195 Berlin \\ Germany \\ Fax: $+49-30-8445-1761$ \\ E-mail: ibrahim.chahoud@medizin.fu- berlin.de \\ F.J.R. Paumgartten is the recipient of a CNPq research fellowship and his present address \\ is Laboratório de Toxicologia Ambiental, Departamento de Ciências Biológicas, Escola Nacional de Saúde Pública, Fundação Oswaldo Cruz, Rio de Janeiro, RJ, Brasil.}

Received June 18, 2004 Accepted January 20, 2005 $\ldots \ldots \ldots \ldots \ldots \ldots$

\begin{abstract}
We investigated the relationship between fetal body weight at term (pregnancy day 21) and the extent of ossification of sternum, metacarpus, metatarsus, phalanges (proximal, medial and distal) of fore- and hindlimbs and cervical and coccygeal vertebrae in Wistar rats. The relationships between fetal body weight and sex, intrauterine position, uterine horn, horn size, and litter size were determined using historical control data (7594 fetuses; 769 litters) of untreated rats. Relationships between body weight and degree of ossification were examined in a subset of 1484 historical control fetuses (154 litters) which were subsequently cleared and stained with alizarin red S. Fetal weight was independent of horn size, uterine horn side (left or right) or intrauterine position. Males were heavier than females and fetal weight decreased with increasing litter size. Evaluation of the skeleton showed that ossification of sternum, metacarpus and metatarsus was extensively complete and independent of fetal weight on pregnancy day 21 . In contrast, the extent of ossification of fore- and hindlimb phalanges and of cervical and sacrococcygeal vertebrae was dependent on fetal body weight. The strongest correlation between body weight and degree of ossification was found for hindlimb, medial and proximal phalanges. Our data therefore suggest that, in full-term rat fetuses (day 21 ), reduced ossification of sternum, metacarpus and metatarsus results from a localized impairment of bone calcification (i.e., a malformation or variation) rather than from general growth retardation and that ossification of hindlimb (medial and proximal) phalanges is a good indicator of treatment-induced fetal growth retardation.
\end{abstract}

Key words

- Ossification centers

- Fetal skeleton

- Delayed fetal growth

- Prenatal growth retardation

- Malformation

- Embryotoxicity

\section{Introduction}

In developmental toxicity studies, a reduction of average fetal body weight at term is usually considered to result from a substance-induced prenatal growth retardation. Spongy and incompletely or poorly ossified bones as well as unossified ossification cen- ters have also been taken as indicators of delayed ossification of the fetal skeleton. However, the relationship between body weight at term and extent of ossification of the fetal skeleton has not been extensively investigated. A body weight reduction, or a fetus small for gestational age does not necessarily imply that growth retardation pro- 
cess had occurred. By definition, prenatal growth retardation means that the affected fetus developed slower than normal fetuses, so that at the end of pregnancy it was in a relatively earlier stage of development. Although fetal body weight increases progressively with gestational age, it also depends on other variables, such as genetic background and environmental factors. A smaller and lighter fetus, therefore, does not necessarily mean that its growth was retarded, or that it is less mature than expected for the gestational age. The same holds true for a reduced degree of ossification of some fetal skeleton bones. Although bone ossification advances with gestational age, a substanceinduced impairment of calcification of a particular bone is not necessarily secondary to a slower development of the skeleton as a whole.

Aliverti et al. (1) studied the development of rat skeleton from pregnancy day 19 to 21 by counting the number of ossification centers in sternum, cervical and caudal vertebrae, metacarpus, metatarsus, and foreand hindpaw proximal phalanges. Their results clearly showed that, in each of the areas evaluated, the number of ossification centers increased as gestation age increased from 19 to 21 days. Based on their findings, Aliverti et al. (1) suggested that the number of ossification centers in these areas would provide a reliable quantitative index for evaluating fetal growth retardation on pregnancy day 21 . These authors, however, did not investigate the relationship between degree of skeleton ossification and fetal body weight.

Ariyuki et al. (2), on the other hand, examined the relationship between body weight and ossification of coccygeal vertebrae in full-term mouse and rat fetuses. In both species, a positive correlation was found between fetal body weight and number of sacrococcygeal ossified vertebrae. In a subsequent study, Ariyuki et al. (3) evaluated the relationship between body weight and degree of ossification of sternum, sacrococ- cygeal vertebrae, forepaw proximal phalanges, and supraoccipital bone in rat fetuses removed by cesarean section on days 19, 20 and 21 of pregnancy. Although Ariyuki et al. (3) provided very interesting data demonstrating a parallel increase in body weight and extent of ossification of some skeleton areas between pregnancy days 19 and 21, they did not attempt to correlate body weight with degree of ossification in full-term rat fetuses. It is of note that a growth-retarded fetus at term is expected to present both a size (body weight) reduction as well as a decrease of ossification of certain skeleton areas.

In the present study, we examined the relationships between body weight and extent of skeleton ossification in rat fetuses removed by cesarean section on pregnancy day 21. Dependency of fetal weight on other variables such as gender, litter size, uterine horn size, and relative position within the uterine horns was also evaluated.

\section{Material and Methods}

The relationship between rat fetal body weight and other parameters evaluated after cesarean section (sex, litter size, incidence of resorptions, intrauterine position, uterine horn side, horn size) was analyzed using our historical control records of 7594 fetuses from 769 litters. The relationship between body weight and degree of ossification was examined in a subset of 1484 historical control fetuses (154 litters) which were subsequently cleared and stained with alizarin red S for skeleton evaluation. All historical control data were from untreated (Bor: Wistar spf; TNO) female rats, weighing approximately 200 g, supplied by Fa. Winckelmann, Borchen, Germany. Upon arrival at the Institute of Clinical Pharmacology and Toxicology (FU, Berlin) rats were housed in standard plastic cages (Makrolon ${ }^{\circledR}$ ) and kept in animal quarters under specific-pathogen-free conditions at constant temperature (21 \pm 
$\left.1^{\circ} \mathrm{C}\right)$, relative humidity $(50 \pm 5 \%)$ and a 12 h light/dark cycle (lights on at 9:00 am in summer and at 10:00 am in winter). The animals received a standard diet for laboratory rodents (Altromin ${ }^{\circledR}$ 1324, Lage, Germany) and tap water ad libitum.

\section{Mating procedure}

Mating was accomplished by placing three females in the cage of one male for $3 \mathrm{~h}$ at the end of the dark period (6:00 to 9:00 h). The first $24 \mathrm{~h}$ after spermatozoa were found in the vaginal smears were considered as pregnancy day 0 (4).

\section{Cesarean section}

On pregnancy day 21 dams were killed by decapitation and gravid uteri were removed with their contents and weighed. Implantation sites were determined by the method of Salewski (5). The number of living and dead fetuses and resorptions, as well as their intrauterine positions were recorded. Living fetuses were individually weighed, sexed, numbered with a marker pen, examined for external malformations under a stereomicroscope, and fixed in 5\% (w/v) formalin. Fetal sex was further confirmed by looking for testes or ovaries during microdissection or evisceration. For skeletal evaluation some litters were further cleared and stained with alizarin red $\mathrm{S}$ by the method of Dawson (6).

\section{Statistical analysis}

Data were analyzed statistically using a SAS software (7). The statistical significance of relationships between fetal body weight and number of ossification centers in the examined skeleton areas (sternum, metacarpus, proximal, medial and distal phalanges of fore- and hindlimbs, as well as cervical and coccygeal vertebrae) was tested by multifactorial analysis of variance and by the
Student $t$-test. Regression models were employed to test relationships between body weight and number of ossification centers in phalanges of fore- and hindlimbs, and in cervical and coccygeal vertebrae. A quadratic regression model was applied to test the relationships between body weight and degree of ossification of proximal and medial phalanges of fore- and hindlimbs, while a linear regression model was used for the remaining areas. Differences were considered to be statistically significant when $\mathrm{P}<$ 0.05 .

\section{Results}

\section{Fetal body weight, resorption incidence and} litter size

As shown in Figure 1A and Table 1, body weights of 7594 full-term live fetuses of our historical control records fit a normal distribution with a mean of $4.5 \mathrm{~g}$ and a standard deviation of $0.5 \mathrm{~g}$. These fetuses were from 769 litters ranging in size from one to 16 fetuses, with a mean litter size $( \pm S D)$ of 9.9

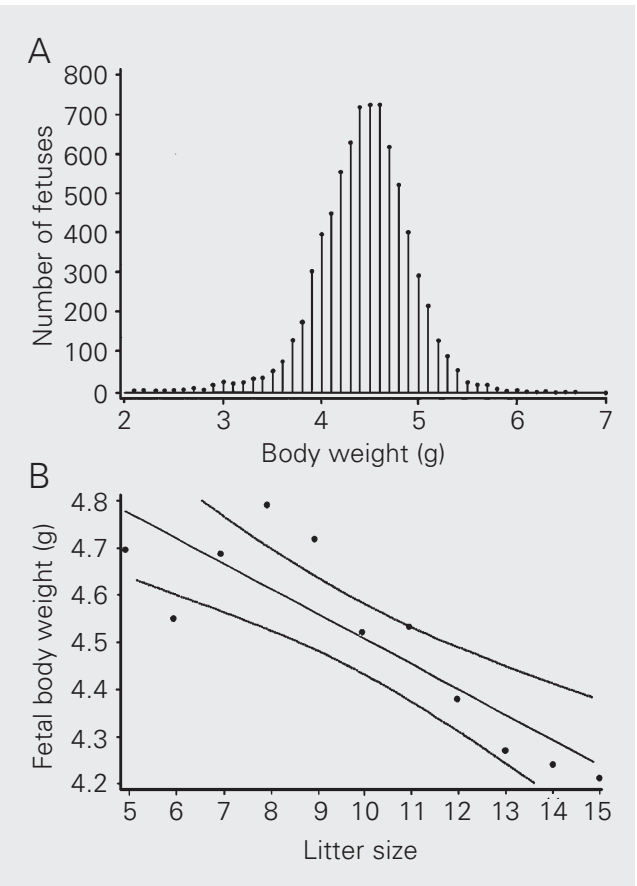

Figure 1. Fetal body weight and litter size. Panel $A$ shows the frequency distribution of body weights (g) of 7594 fetuses (469 litters) examined in the present study. Panel $B$ shows the linear regression ( $r=-0.99)$ and $95 \%$ confidence limits of mean fetal body weights (g) plotted against litter sizes. All fetuses were from untreated Wistar rats and were obtained by cesarean section on pregnancy day 21 
\pm 2.6 fetuses. The overall incidence of resorptions (mean $\pm \mathrm{SD}$ ) in the 769 litters evaluated in this study was $0.73 \pm 1.28$. Table 2 presents data on litter distribution

Table 1. Sex, number and body weight of rat fetuses located in the right and left uterine horns.

\begin{tabular}{lrrr}
\hline Uterine horn & $N$ & $\%$ & $\begin{array}{r}\text { Fetal body } \\
\text { weight (g) } \\
\text { (mean } \pm \text { SD) }\end{array}$ \\
& & & \\
\hline $\begin{array}{l}\text { Both horns } \\
\text { M + F }\end{array}$ & 7594 & 100.0 & $4.5 \pm 0.5$ \\
M & 3816 & 50.3 & $4.6 \pm 0.5$ \\
F & 3775 & 49.7 & $4.4 \pm 0.4^{*}$ \\
Right horn & & & \\
M + F & 3792 & 49.9 & $4.5 \pm 0.5$ \\
M & 1906 & 25.1 & $4.6 \pm 0.5$ \\
F & 1884 & 24.8 & $4.4 \pm 0.5^{*}$ \\
Left horn & & & \\
M + F & 3802 & 50.1 & $4.5 \pm 0.5$ \\
M & 1910 & 25.2 & $4.6 \pm 0.5$ \\
F & 1891 & 24.9 & $4.4 \pm 0.4^{*}$ \\
\hline
\end{tabular}

All fetuses were from untreated Wistar rats and were obtained by cesarean section on pregnancy day $21 . \mathrm{M}=$ male; $\mathrm{F}=$ female

${ }^{*} \mathrm{P}<0.05$ compared to males (Student $t$-test).
(\%) according to litter size (taking into account only live fetuses) and the number of resorptions, and shows that $468(60.8 \%)$ of the examined uteri with at least one live fetus did not exhibit any resorption. Linear regression analysis of data from litters without resorptions, and with 5 to 15 fetuses, indicated that fetal body weight correlated inversely $(r=-0.99)$ with litter size (Figure 1B).

Fetal body weight, sex, intrauterine position and horn side and size

The number of male fetuses was slightly higher than that of females, and males were also heavier than females (Table 1) and these sex-related differences were consistently noted when each horn side was analyzed separately or both were analyzed together, and horn side location had no influence on fetal body weight (Table 1). When litter size was controlled, horn size (data not shown) and relative position of the fetus within each uterine horn had no apparent effect on body weight at term as well (Table 3).

Table 2. Relationship between the number of fetuses (total litter size) and fetal resorptions per dam.

\begin{tabular}{|c|c|c|c|c|c|c|c|c|c|c|c|}
\hline \multirow{2}{*}{$\begin{array}{l}\text { Total litter } \\
\text { size }\end{array}$} & \multirow{2}{*}{$\begin{array}{c}\text { Number of } \\
\text { litters }\end{array}$} & \multicolumn{10}{|c|}{ Number of resorptions per pregnant dam (\% of dams) } \\
\hline & & 0 & 1 & 2 & 3 & 4 & 5 & 6 & 7 & 8 & 9 \\
\hline 1 & 2 & 100.0 & - & - & - & - & - & - & - & - & - \\
\hline 2 & 16 & 6.3 & 25.0 & 12.5 & 6.3 & 18.8 & 6.3 & 12.5 & - & 6.3 & 6.3 \\
\hline 3 & 7 & 14.3 & 14.3 & 28.6 & - & 42.9 & - & - & - & - & - \\
\hline 4 & 17 & 5.9 & 11.8 & 11.8 & 23.5 & 17.6 & 11.8 & 5.9 & 5.9 & - & 5.9 \\
\hline 5 & 19 & 31.6 & 15.8 & 5.3 & 21.1 & 15.8 & 5.3 & 5.3 & - & - & - \\
\hline 6 & 18 & 22.2 & 11.1 & 16.7 & 22.2 & 16.7 & 5.6 & 5.6 & - & - & - \\
\hline 7 & 33 & 33.3 & 15.2 & 21.2 & 18.2 & 6.1 & - & 3.0 & 3.0 & - & - \\
\hline 8 & 54 & 38.9 & 24.1 & 25.9 & 5.6 & 3.7 & 1.9 & - & - & - & - \\
\hline 9 & 102 & 46.1 & 43.1 & 6.9 & 3.9 & - & - & - & - & - & - \\
\hline 10 & 147 & 67.3 & 27.9 & 2.7 & 1.4 & 0.7 & - & - & - & - & - \\
\hline 11 & 153 & 71.2 & 23.5 & 4.6 & 0.7 & - & - & - & - & - & - \\
\hline 12 & 114 & 78.9 & 16.7 & 4.4 & - & - & - & - & - & - & - \\
\hline 13 & 51 & 84.3 & 13.7 & 2.0 & - & - & - & - & - & - & - \\
\hline 14 & 30 & 90.0 & 10.0 & - & - & - & - & - & - & - & - \\
\hline 15 & 4 & 100.0 & - & - & - & - & - & - & - & - & - \\
\hline 16 & 2 & 100.0 & - & - & - & - & - & - & - & - & - \\
\hline \multicolumn{2}{|c|}{ Total of litters (N) } & 468 & 180 & 55 & 29 & 20 & 6 & 6 & 2 & 1 & 2 \\
\hline
\end{tabular}

Data are reported as the percentage of dams with litters of a given size that also exhibited 0 to 9 resorptions. A total of $468(60.8 \%)$ of the examined uteri with at least one live fetus did not exhibit any resorption. 


\section{Fetal body weight and extent of skeleton ossification}

Metatarsus (10 ossification centers) as well as sternum (6 sternebrae) bones were already completely ossified (100\%) in almost all full-term fetuses examined in this study. Ossification of distal phalanges of both fore- and hindlimbs (95\%) was nearly complete in most of the evaluated fetuses (Table 4) as well. The correlation coefficients ( $r$ ) of linear regression analysis for fetal weight and number of ossification centers in forepaw and hindpaw distal phalanges were 0.22 and 0.27 , respectively. The degree of ossification of the foregoing skeleton areas on pregnancy day 21 , therefore, showed no dependence on fetal body weight (Tables 5, 6 and 7). Almost all fetuses examined on pregnancy day 21 - irrespective of their body weights - had $80 \%$ of the maximum number of metacarpal ossification centers (Tables 4 and 5), a finding suggesting that the extent of ossification of this bone is

\begin{tabular}{l} 
Table 3. Body weight of rat fetuses according to their relative position within the uterine horn. \\
$\begin{array}{l}\text { Horn Number } \\
\text { size of litters }\end{array}$ \\
\cline { 3 - 10 }
\end{tabular}

Fetuses were obtained by cesarean section on pregnancy day 21. Analysis included only litters without resorptions and with the same number of fetuses in the right and left uterine horns. Data are reported as means $\pm \mathrm{SD}$, in grams.

+Numbers from 1 to 8 indicate relative position from cervix to ovary extremity. Horn size = number of fetuses per horn.

Table 4. Extent of skeleton ossification of male and female rat fetuses on pregnancy day 21.

\begin{tabular}{lcccc}
\hline Skeleton area & \multicolumn{4}{c}{ Number of ossification centers } \\
\cline { 2 - 5 } & $\begin{array}{c}\text { Maximum } \\
\text { number }\end{array}$ & $\begin{array}{c}\text { Males } \\
\text { (mean } \pm \text { SD) }\end{array}$ & $\begin{array}{c}\text { Females } \\
\text { (mean } \pm \text { SD) }\end{array}$ & $\begin{array}{c}\text { All } \\
\text { (mean } \pm \text { SD) }\end{array}$ \\
\hline Forelimbs & & & & \\
$\quad$ Metacarpus & $10(100 \%)$ & $8.0 \pm 0.2(80 \%)$ & $8.0 \pm 0.1(80 \%)$ & $8.0 \pm 0.1(80 \%)$ \\
$\quad$ Medial and proximal phalanges & $18(100 \%)$ & $6.4 \pm 2.1(36 \%)$ & $6.3 \pm 2.1(35 \%)$ & $6.3 \pm 2.1(35 \%)$ \\
$\quad$ Distal phalanges & $10(100 \%)$ & $9.4 \pm 1.6(94 \%)$ & $9.6 \pm 1.2(96 \%)$ & $9.5 \pm 1.4(95 \%)$ \\
Hindlimbs & & & & \\
$\quad$ Medial and proximal phalanges & $18(100 \%)$ & $5.1 \pm 3.3(28 \%)$ & $4.8 \pm 3.3(27 \%)$ & $4.9 \pm 3.3(27 \%)$ \\
$\quad$ Distal phalanges & $10(100 \%)$ & $9.8 \pm 1.0(98 \%)$ & $9.8 \pm 0.9(98 \%)$ & $9.8 \pm 1.0(98 \%)$ \\
Cervical vertebrae & $7(100 \%)$ & $3.5 \pm 1.9(49 \%)$ & $3.2 \pm 1.8(46 \%)$ & $3.3 \pm 1.9(47 \%)$ \\
Coccygeal vertebrae & $28(100 \%)$ & $9.1 \pm 1.3(33 \%)$ & $9.0 \pm 1.3(32 \%)$ & $9.0 \pm 1.3(32 \%)$ \\
\hline
\end{tabular}

Data are reported as the number (mean \pm SD) of ossification centers and as the percentage of the maximum number of ossification centers for the skeleton area. A total of 1484 fetuses were examined. +Numbers of ossification centers are shown as the total number for both right and left limbs. No statistically significant difference ( $P>0.05$ ) was found between males and females (Mann-Whitney U-test). 
independent of fetal weight. The two metacarpal bones that were not yet ossified at term were those of finger 1 (one on each forepaw) that, in the rat, ossify after birth. Proximal and medial phalanges of fore- and hindlimbs, on the other hand, were rather incompletely ossified on pregnancy day 21 . It is of note that the degree of ossification of medial and proximal phalanges at near term pregnancy proved to be dependent on fetal body weight, varying from 14 to $39 \%$ from lighter to heavier fetuses, and from 5 to $48 \%$ of the maximum number of ossification centers in fore- and hindpaws, respectively (Tables 5 and 6, Figure 2A,B).

The extent of ossification of rat fore- and hindpaws on pregnancy day 21 and postnatal day 7 is illustrated in Figure 3. As shown in panel $3 \mathrm{~B}$, except for finger 1 (the smallest digit), metacarpal bones as well as proximal, medial and distal phalanges were usually ossified in forepaw fingers on postnatal day 7. On pregnancy day 21 (panel $3 \mathrm{~A}$ ), four metacarpal bones, four proximal and all dis-

Table 5. Relationship between body weight and extent of ossification of metacarpus and forelimb phalanges in rat fetuses on pregnancy day 21.

\begin{tabular}{|c|c|c|c|c|}
\hline \multirow{2}{*}{$\begin{array}{l}\text { Body weight } \\
\text { interval (g) }\end{array}$} & \multirow[t]{2}{*}{ Number of fetuses } & \multicolumn{3}{|c|}{ Number of ossification centers ${ }^{+}($mean $\pm S D)$} \\
\hline & & Metacarpus & Proximal and medial phalanges & Distal phalanges \\
\hline $\mathrm{BW}<3.4$ & 22 & $7.7 \pm 0.9(77 \%)$ & $2.8 \pm 2.5(16 \%)$ & $9.1 \pm 2.3(91 \%)$ \\
\hline $3.4 \leq \mathrm{BW}<3.8$ & 51 & $8.0 \pm 0.1(80 \%)$ & $4.0 \pm 2.2(22 \%)$ & $9.5 \pm 1.8(94 \%)$ \\
\hline $3.8 \leq \mathrm{BW}<4.2$ & 192 & $8.0 \pm 0.1(80 \%)$ & $5.4 \pm 2.1(30 \%)$ & $9.4 \pm 1.6(94 \%)$ \\
\hline $4.2 \leq \mathrm{BW}<4.6$ & 527 & $8.0 \pm 0.1(80 \%)$ & $6.1 \pm 2.2(34 \%)$ & $9.5 \pm 1.3(95 \%)$ \\
\hline $4.6 \leq \mathrm{BW}<5.0$ & 477 & $8.0 \pm 0.0(80 \%)$ & $6.9 \pm 1.8(38 \%)$ & $9.5 \pm 1.4(95 \%)$ \\
\hline $5.0 \leq \mathrm{BW}<5.4$ & 177 & $8.0 \pm 0.0(80 \%)$ & $7.4 \pm 1.4(41 \%)$ & $9.6 \pm 1.2(96 \%)$ \\
\hline $5.4 \leq \mathrm{BW}$ & 38 & $8.0 \pm 0.0(80 \%)$ & $7.8 \pm 0.7(43 \%)$ & $9.5 \pm 1.8(95 \%)$ \\
\hline
\end{tabular}

Data are reported as the number (mean \pm SD) of ossification centers and as the percentage of the maximum number of ossification centers for the skeleton area. A total of 1484 fetuses were examined.

${ }^{+}$Numbers of ossification centers are shown as the total number for both right and left limbs. BW $=$body weight. Maximum number of ossification centers $(100 \%)$ : metacarpus $=10$; proximal + medial phalanges $=$ 18; distal phalanges $=10$.

Table 6. Relationship between body weight and extent of ossification of hindlimb phalanges in rat fetuses on pregnancy day 21.

\begin{tabular}{|c|c|c|c|}
\hline \multirow{2}{*}{$\begin{array}{l}\text { Body weight } \\
\text { interval (g) }\end{array}$} & \multirow[t]{2}{*}{ Number of fetuses } & \multicolumn{2}{|c|}{ Number of ossification centers ${ }^{+}($mean \pm SD $)$} \\
\hline & & Proximal and medial phalanges & Distal phalanges \\
\hline $\mathrm{BW}<3.4$ & 22 & $1.0 \pm 1.2(6 \%)$ & $8.6 \pm 3.5(86 \%)$ \\
\hline $3.4 \leq \mathrm{BW}<3.8$ & 51 & $1.6 \pm 2.3(9 \%)$ & $9.4 \pm 2.1(94 \%)$ \\
\hline $3.8 \leq \mathrm{BW}<4.2$ & 192 & $2.7 \pm 2.2(15 \%)$ & $9.8 \pm 0.8(98 \%)$ \\
\hline $4.2 \leq \mathrm{BW}<4.6$ & 527 & $4.3 \pm 2.9(24 \%)$ & $9.8 \pm 1.0(98 \%)$ \\
\hline $4.6 \leq \mathrm{BW}<5.0$ & 477 & $5.9 \pm 3.0(33 \%)$ & $9.8 \pm 0.7(98 \%)$ \\
\hline $5.0 \leq \mathrm{BW}<5.4$ & 177 & $7.5 \pm 3.0(42 \%)$ & $9.9 \pm 0.5(99 \%)$ \\
\hline $5.4 \leq \mathrm{BW}$ & 38 & $9.5 \pm 1.9(53 \%)$ & $9.9 \pm 0.5(99 \%)$ \\
\hline \multicolumn{4}{|c|}{$\begin{array}{l}\text { Data are reported as the number (mean } \pm \text { SD) of ossification centers and as the percentage of the maximum } \\
\text { number of ossification centers for the skeleton area. A total number of } 1484 \text { fetuses were examined. } \\
+ \text { Numbers of ossification centers are shown as the total number for both right and left limbs. BW = body } \\
\text { weight. Maximum number of ossification centers }(100 \%) \text { : proximal + medial phalanges }=20 \text {; distal phalan- } \\
\text { ges }=10 \text {. }\end{array}$} \\
\hline
\end{tabular}


Table 7. Relationship between body weight and extent of ossification of cervical and sacrococcygeal vertebrae in rat fetuses on pregnancy day 21.

\begin{tabular}{lccc}
\hline $\begin{array}{l}\text { Body weight } \\
\text { interval }(g)\end{array}$ & Number of fetuses & \multicolumn{2}{c}{ Number of ossification centers (mean \pm SD) } \\
\cline { 3 - 4 } & & Cervical vertebrae & Sacrococcygeal vertebrae \\
\hline $\mathrm{BW}<3.4$ & 22 & $0.8 \pm 0.9(12 \%)$ & $7.0 \pm 1.0(25 \%)$ \\
$3.4 \leq \mathrm{BW}<3.8$ & 51 & $1.9 \pm 1.4(27 \%)$ & $7.9 \pm 1.2(28 \%)$ \\
$3.8 \leq \mathrm{BW}<4.2$ & 192 & $2.4 \pm 1.7(34 \%)$ & $8.3 \pm 1.0(30 \%)$ \\
$4.2 \leq \mathrm{BW}<4.6$ & 527 & $3.0 \pm 1.8(43 \%)$ & $8.7 \pm 1.0(31 \%)$ \\
$4.6 \leq \mathrm{BW}<5.0$ & 477 & $3.8 \pm 1.8(55 \%)$ & $9.3 \pm 1.0(33 \%)$ \\
$5.0 \leq \mathrm{BW}<5.4$ & 177 & $4.0 \pm 1.8(57 \%)$ & $12.0 \pm 1.05(35 \%)$ \\
$5.4 \leq \mathrm{BW}$ & 38 & $5.4 \pm 1.6(77 \%)$ & $2.0(43 \%)$ \\
\hline
\end{tabular}

Data are reported as the number (mean \pm SD) of ossification centers and as the percentage of the maximum number of ossification centers for the skeleton area. A total number of 1484 fetuses were examined. $\mathrm{BW}=$ body weight. Maximum number of ossification centers (100\%): cervical vertebrae $=7$; coccygeal vertebrae $=28$.

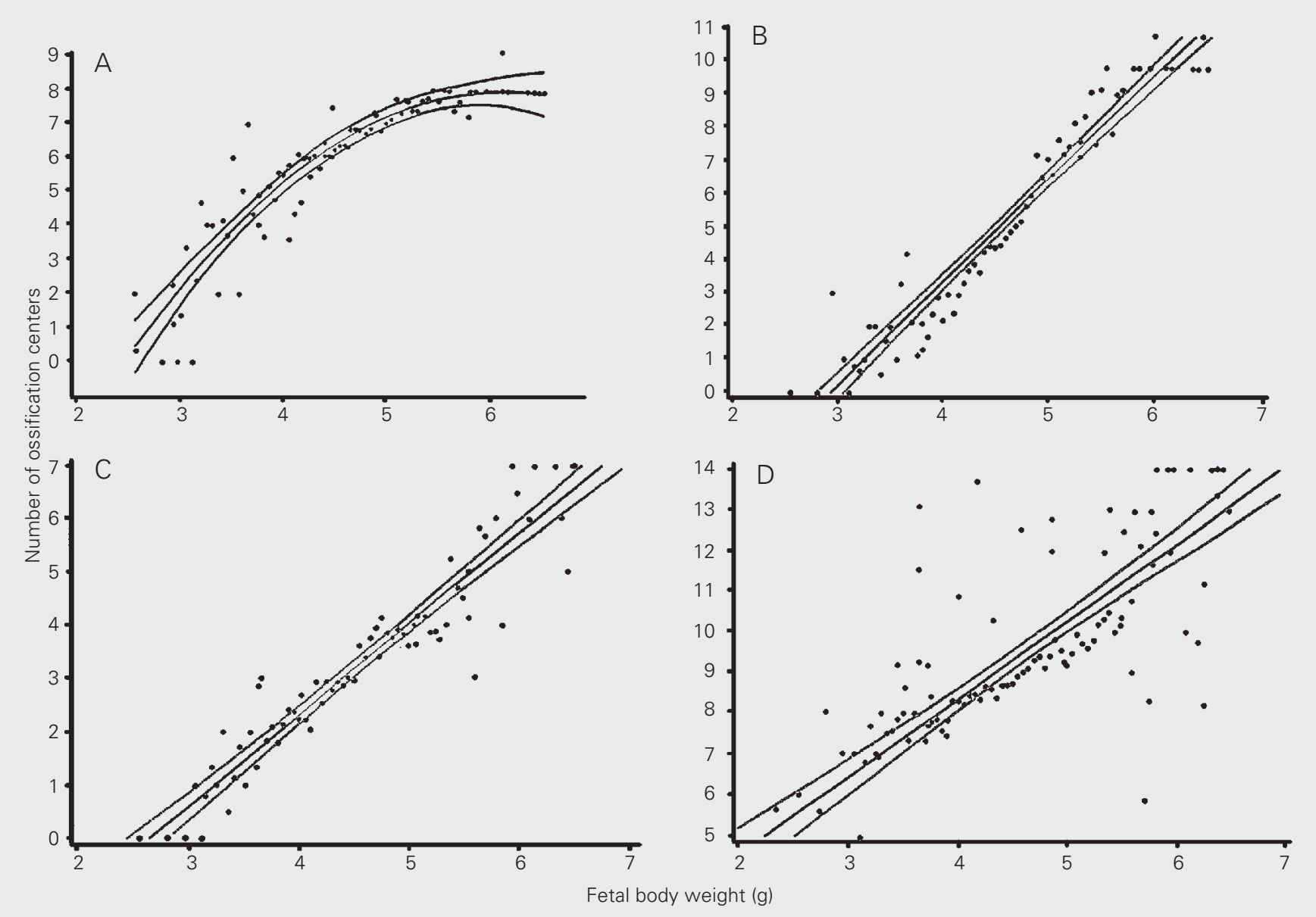

Figure 2. Relationship between fetal body weight (g) on pregnancy day 21 and extent of ossification (number of ossification centers) of proximal and medial phalanges of fore- (panel A) and hindpaws (panel B), as well as cervical vertebrae (panel C) and sacrococcygeal vertebrae (panel D). Regression lines are shown with their respective 95\% confidence limits. Quadratic regression models were used for fore- and hindpaw phalanges (A and B) and linear regression was used for cervical and sacrococcygeal veterbrae (C and D). Correlation coefficients were $0.88,0.97,0.95$, and 0.90 for $A, B, C$, and D, respectively. Data were for 1484 fetuses (154 litters) from untreated Wistar rats. 
tal forepaw phalanges were already ossified in most fetuses. When day-21 fetuses exhibited fewer ossified proximal phalanges (panel $3 \mathrm{E}$ ), the ossified ones were, as a rule, those of finger 3 (where ossification seems to begin) and the nearest fingers (fingers 4 and 2). On postnatal day 7 (panel 3D), hindpaw toes usually exhibited all five metatarsal bones and all fourteen phalanges ossified. As shown in panel 3C, all metatarsal bones and distal phalanges, and only three proximal phalan-
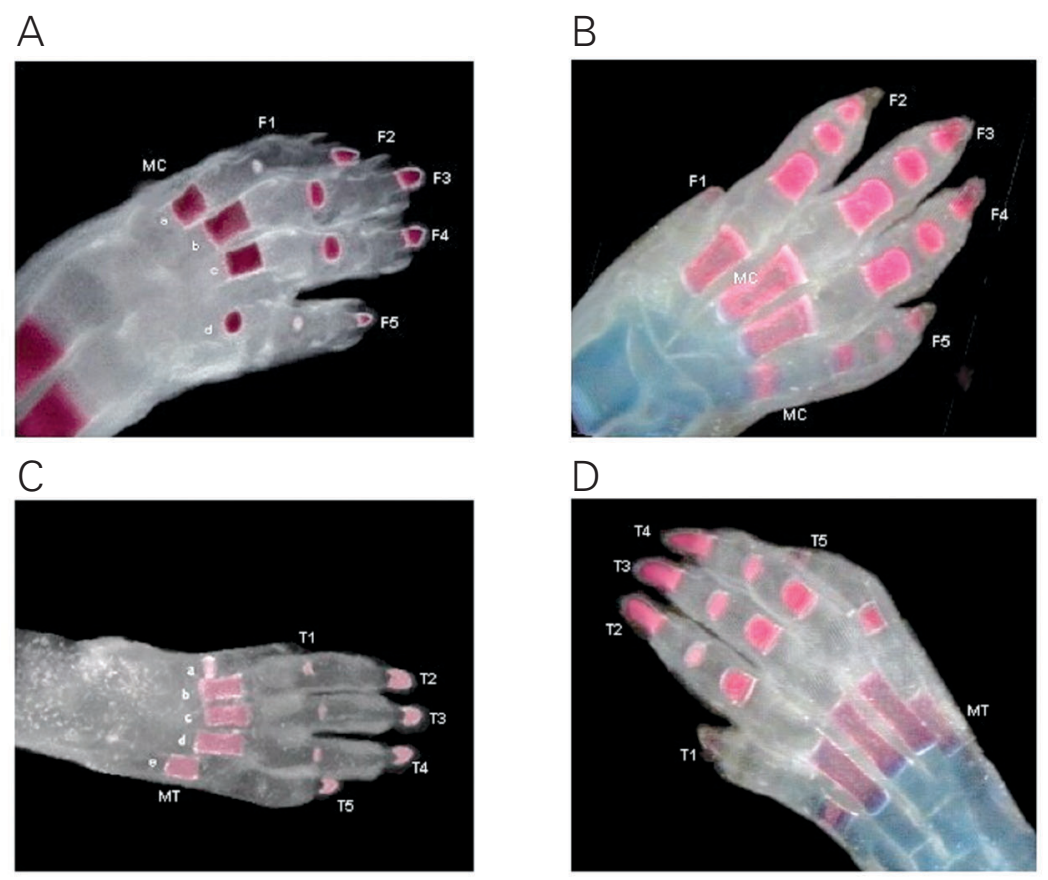

E

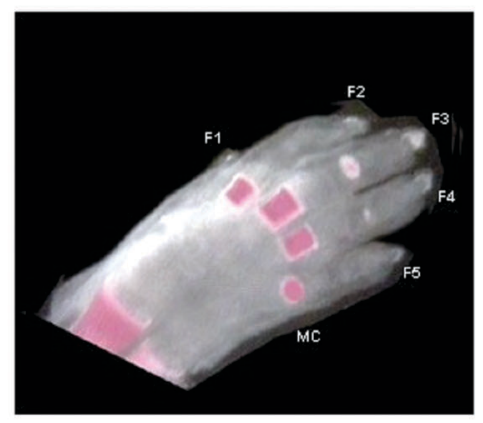

Figure 3. Extent of ossification of fore- and hindpaw bones in the rat on pregnancy day 21 and postnatal day 7. Panels $A$ and $D$ show the forepaws and panel $C$ shows the hindpaws of pregnancy day-21 fetuses cleared and stained with alizarin red S. Panels $B$ (forepaw) and $E$ (hindpaw) show 7-day-old pups cleared and stained with alizarin red S (red color: calcified bones) and Alcian blue (blue color: cartilages). $\mathrm{MC}=$ metacarpus, $\mathrm{MT}=$ metatarsus, fingers (F1-F5), and toes (T1-T5) were numbered from the medial side. ges were ossified in the hindpaw of this pregnancy day 21 fetus. Although we had decided to count proximal and medial phalanges together, we seldom found medial phalanges of fore- or hindpaws already ossified on pregnancy day 21. Ossified medial phalanges were found only among the heaviest day-21 fetuses.

Ossification of cervical and sacrococcygeal vertebrae was also rather incomplete on pregnancy day 21 (Tables 4 and 7). In both cases, the number of ossified centers was found to be clearly dependent on fetal body weight, ranging from 12 to $77 \%$ from lighter to heavier fetuses and from 25 to $43 \%$ of the maximum number of ossified centers in the cervical and sacrococcygeal vertebrae, respectively (Table 7, Figure 2C,D).

No sex-related difference was found in any of the skeletal areas evaluated in the present study regarding the extent of ossification on pregnancy day 21 (Table 4). Comparisons of the number of ossification centers found in fetuses located in the left uterine horn with that of those located in the right horn - together and separately according to each body weight interval - also showed no difference between horn side locations (data not shown).

\section{Discussion}

The data reported in the present paper indicate that the body weight of full-term rat fetuses is independent of the uterine horn side where the fetus is located and, once litter size is controlled, it is also independent of horn size and of relative position of the fetus within the horn. The results clearly demonstrated, however, that males were slightly (approximately $4.5 \%$ ) heavier than females and that fetal body weight at term was inversely correlated with litter size.

Data showing that rat fetal weight at term is not influenced by whether the fetus comes from the left or the right uterine horn were also reported by Barr et al. (8). Conflicting 
results, however, have been published on a possible relation between fetal body weight and intrauterine horn position in mice, rats and rabbits. McLaren and Michie (9), for instance, reported a position effect in mice according to a U-shaped pattern, i.e., the heaviest fetuses were located toward the ends of the uterine horn and the lightest ones in the middle. von Domarus et al. (10), on the other hand, reported that mouse embryos (on pregnancy day 14) were lighter both at the ovarian and cervical ends (i.e., an inverted U pattern). A further paper by the same authors (11) reported a somewhat different position effect in mice (on day 19), i.e., fetuses on the cervical end were lighter, those in the middle were roughly the same and those of the ovarian end were heavier than the average. In rabbits, a weight gradient from the ovarian to the cervical end of the uterine horns was found by Rosahn and Green (12). A few studies performed on rats using different methods to define the position of the fetuses have apparently come to a common conclusion that fetuses located in the middle horn position are heavier than those at both ends of the uterine horn $(8,13,14)$. Barr and Brent (15) also found that, in the rat, such an association between fetal body weight and intrauterine position may not be dependent on hemodynamic factors such as the loopartery configuration that provides blood supply to the uterine horn. Although several studies have reported a position effect on fetal weight in polytocous mammals, the nature of such a position effect has been shown to vary from species to species and, sometimes, between two studies on the same species, and its possible underlying causes remain obscure. In our rat strain, after controlling for possible confounding factors such as litter and horn sizes and occurrence of resorptions, we did not observe any trend toward an effect of intrauterine position on fetal body weight at term.

The present data clearly show that almost all fetuses examined had all six (100\%) sternebrae ossified on pregnancy day 21 , a finding that agrees with previous reports by Aliverti et al. (1) and Ariyuki et al. (3). The ossification of the metatarsus and of the fore- and hindpaw distal phalanges was also nearly complete in almost all fetuses evaluated in this study. Ossification of the metacarpus, however, was less complete than that of metatarsus and only 8 of 10 (both forepaws together) metacarpus bones were ossified on pregnancy day 21 (Table 5). A similar high degree of metatarsus ossification $(97.2 \%$ of fetuses with 5 ossification centers in one hindpaw) as well as metacarpus ossification (98.6\% of fetuses with 4 ossification centers in one forepaw) were also observed by Aliverti et al. (1) on day 21. Our results additionally demonstrate that a high degree of ossification of sternum, metatarsus, metacarpus, and distal phalanges was observed on pregnancy day 21 in almost all fetuses examined irrespective of gender or body weight. Contrasting with the extensive ossification of the above skeleton areas, the proximal and medial phalanges of fore- and hindpaws as well as of cervical and sacrococcygeal vertebrae were still incompletely ossified on gestational day 21 . Untreated rat fetuses from our historical control records had, on average, only $35 \%$ of forepaw, and $28 \%$ of hindpaw (medial + proximal) phalanges ossified on day 21. The proximal phalanges of both limbs or only those of the forepaws were counted by Aliverti et al. (1) and Ariyuki et al. (3), respectively. The two studies found that at least 4 proximal forepaw phalanges were ossified in 94.4 (1) and $80 \%$ (2) of fetuses on day 21. Aliverti et al. (1) also reported that progress of ossification in the hindlimbs was slower than that in the forelimbs because only $30.5 \%$ of day- 21 fetuses had at least 4 proximal phalanges of each hindpaw ossified. The present data support this view since day- 21 fetuses presented, on average, ossification of $35 \%$ of the maximum number of proximal and medial phalanges of forepaws against $27 \%$ of those of 
hindpaws (Table 4). Our results also show that, in pregnancy day 21 fetuses, the number of ossified proximal plus medial phalanges - both in fore- and hindpaws - was positively correlated with body weight (Tables 5 and 6, Figure 2A,B). In the present study, the number of ossified cervical vertebrae also strongly correlated with fetal body weight (Table 7, Figure 2C). According to the results reported by Aliverti et al. (1), no cervical vertebra was ossified in day-19 fetuses, with the first signs of ossification of this area appearing on day 20 , and $81.9 \%$ of all day21 fetuses had at least 5 (i.e., $>71.4 \%$ ) of all cervical vertebrae ossified.

However, our results indicated that ossification of the cervical vertebrae of day- 21 fetuses depends on their body weights. The mean $( \pm$ SD) number of ossified cervical vertebrae of all day-21 fetuses evaluated in this study was $3.3 \pm 1.9$ (Table 4), i.e., $47.1 \%$ of all cervical vertebrae, but the extent of ossification ranged from $12 \%$, among fetuses weighing less than $3.4 \mathrm{~g}$, to as much as $77 \%$, among those with body weights equal to or higher than $5.4 \mathrm{~g}$ (Table 7).

As shown in the present study, and previously reported in the literature (1-3), ossification of sacrococcygeal vertebral bodies is still in progress on pregnancy day 21 . Our data indicated that, on average, only $32 \%$ of sacrococcygeal veterbrae are already ossified in day-21 rat fetuses. As noted with proximal and medial phalanges and cervical vertebral bodies, the extent of ossification of sacrococcygeal vertebrae on day 21 also correlated positively with fetal body weight, ranging from $25 \%$ in the lightest group to $43 \%$ among the heaviest fetuses (Table 7 , Figure 2D).

In the present study, skeleton areas whose ossification was found to be dependent on fetal weight were those that were still far from being completely ossified on day 21 , i.e., medial and proximal phalanges of forepaws (35\%) and hindpaws (28\%), as well as cervical $(47 \%)$ and sacrococcygeal (32\%) vertebrae. The extent of ossification of these four areas thus seemed to be the most sensitive and reliable index of delayed skeleton ossification in rat fetuses at term (day 21).

Based on the present data, it seems fair to conclude that a lower body weight on day 21 accompanied by a reduced ossification of the above four skeleton areas is a good indicator that fetal development is retarded for gestational age. By definition, prenatal growth retardation means that the extent of fetal development on day 21 corresponds to that observed at an earlier gestational age. In other words, retardation implies both a smaller fetal size and a lower body weight, as well as a less developed skeleton. If fetal body weight and skeleton development are differently affected by a treatment, the process underlying the adverse effect is not merely a prenatal growth retardation. On the other hand, signs of deficient ossification of bones or skeleton areas that, irrespective of fetal body weights, are already extensively ossified on pregnancy day 21 (e.g., sternum, distal phalanges, metacarpus, and metatarsus), cannot be considered to result only from a treatment-induced prenatal growth retardation. This seems to be particularly true for those day-21 fetuses whose body weights are within the range analyzed in the present study.

\section{Acknowledgments}

The authors thank Sérgio N. Kuriyama for excellent editorial assistance and Brigitte Bürkle for technical assistance. 


\section{References}

1. Aliverti V, Bonanomi L, Giavini E, Leone VG \& Mariani $L$ (1979). The extent of fetal ossification as an index of delayed development in teratogenic studies on the rat. Teratology, 20: 237-242.

2. Ariyuki F, Higaki K \& Yasuda M (1980). A study of fetal growth retardation in teratological tests: An examination of the relationship between body weight and ossification of coccygeal vertebrae in mouse and rat fetuses. Teratology, 22: 43-49.

3. Ariyuki $F$, Ishihara $H$, Higaki $K$ \& Yasuda $M$ (1982). A study of fetal growth retardation in teratological tests: Relationship between body weight and ossification of the skeleton in rat fetuses. Teratology, 26: 263-267.

4. Chahoud I \& Kwasigroch TE (1977). Controlled breeding of laboratory animals. In: Neubert D, Merker HJ \& Kwasigroch TE (Editors), Methods in Prenatal Toxicology. Georg Thieme, Stuttgart, Germany, 196-200.

5. Salewski E (1964). Faerbenmethoden zum makroskopischen Nachweis von Implantationsstellen am Uterus der Ratte. NaunynSchmiedebergs Archiv für Experimentelle Pathologie und Pharmakologie, 247: 367.

6. Dawson $A B$ (1926). A note on the staining of the skeleton of cleared specimens with alizarin red S. Stain Technology, 1: 123-124

7. Ray AA (1985). Statistics. SAS User's Guide. Version 5. SAS Insti- tute Inc., Cary, NC, USA.

8. Barr M, Jensh RP \& Brent RL (1970). Prenatal growth in the albino rat: Effects of number, intrauterine position and resorptions. American Journal of Anatomy, 128: 413-428.

9. McLaren A \& Michie D (1960). Control of prenatal growth in mammals. Nature, 187: 363-365.

10. von Domarus $H$, Louton $T$ \& Lange-Wühlisch $F$ (1986). The position effect in mice on day 14. Teratology, 34: 73-80.

11. Louton $T$, von Domarus $H$ \& Hartmann $P$ (1988). The position effect in mice on day 19. Teratology, 38: 67-74.

12. Rosahn PD \& Green HSN (1936). The influence of intrauterine factors on the fetal weight of rabbits. Journal of Experimental Medicine, 63: 901-921.

13. Norman NA \& Bruce NW (1979). Fetal and placental weight relationships in the albino rat near term. Teratology, 19: 245-250.

14. Padmanabhan $R$ \& Singh $S$ (1981). Effect of intrauterine position on foetal weight in CF rats. Indian Journal of Medical Research, 73: 134-139.

15. Barr M \& Brent $R L$ (1970). The relation of the uterine vasculature to fetal growth and the intrauterine position effect in rats. Teratology, 3: 251-260. 